\title{
Effect of metformin on the behavior of dental pulp stem cells cultured on freeze-dried bone allografts
}

\author{
Farnaz Kouhestani ${ }^{1, A, B, E, F}$, Maryam Rezai Rad ${ }^{2, C, E, F}$, Sadra Mohaghegh ${ }^{3, C, D, F}$, Saeed Reza Motamedian ${ }^{4,5, A-C, E, F}$ \\ ${ }^{1}$ Department of Periodontics, School of Dentistry, Tehran University of Medical Sciences, Iran \\ ${ }^{2}$ Dental Research Center, Research Institute of Dental Sciences, Shahid Beheshti University of Medical Sciences, Tehran, Iran \\ ${ }^{3}$ Undergraduate Student, Student Research Committee, School of Dentistry, Shahid Beheshti University of Medical Sciences, Tehran, Iran \\ ${ }^{4}$ Dentofacial Deformities Research Center, Research Institute of Dental Sciences, Shahid Beheshti University of Medical Sciences, Tehran, Iran \\ ${ }^{5}$ Department of Orthodontics, School of Dentistry, Shahid Beheshti University of Medical Sciences, Tehran, Iran \\ A - research concept and design; $\mathrm{B}$ - collection and/or assembly of data; $\mathrm{C}$ - data analysis and interpretation; \\ $D$ - writing the article; $E$ - critical revision of the article; $F$ - final approval of the article
}

Address for correspondence

Saeed Reza Motamedian

E-mail: drmotamedian@gmail.com

Funding sources

Research Institute of Dental Sciences, Shahid Beheshti

University of Medical Sciences, Tehran, Iran.

Conflict of interest

None declared

Received on November 28, 2020

Reviewed on December 21, 2020

Accepted on December 28, 2020

Published online on September 7, 2021

Cite as

Kouhestani F, Rezai Rad M, Mohaghegh S, Motamedian SR.

Effect of metformin on the behavior of dental pulp stem cells cultured on freeze-dried bone allografts. Dent Med Probl. 2021;58(3):343-349. doi:10.17219/dmp/131988

DOI

$10.17219 / \mathrm{dmp} / 131988$

Copyright

○) 2021 by Wroclaw Medical University

This is an article distributed under the terms of the

Creative Commons Attribution 3.0 Unported License (CC BY 3.0)

(https://creativecommons.org/licenses/by/3.0/).

\section{Abstract}

Background. Considering the complications associated with autogenous bone grafting, the use of freezedried bone allograft (FDBA) granules may be considered as an alternative treatment plan.

Objectives. The aim of this study was to evaluate the effect of metformin on both the proliferation and osteogenic capability of dental pulp stem cells (DPSCS) cultured on FDBA granules.

Material and methods. First, a pilot study was conducted only on DPSCs to confirm cellular viability and the osteoinducing effect of $100 \mu \mathrm{mol} / \mathrm{L}$ metformin. Next, the cells were loaded on FDBA granules and treated with and without metformin. Finally, the following analyses were performed: scanning electron microscopy (SEM) (cell attachment); the 3-(4,5-dimethylthiazol-2-yl)-2,5-diphenyltetrazolium bromide (MTT) assay (proliferation); and alkaline phosphatase (ALP) activity analysis (osteogenic differentiation).

Results. The SEM images revealed that metformin enhanced the adhesion of DPSCs on FDBA granules. In addition, metformin was shown to increase cell proliferation/viability from day 1 to day 7. Compared to the control, a significant difference was observed after 7 days of treatment. Metformin enhanced the osteogenic capability of FDBA in both standard and osteoinducing conditions. An increase in ALP activity was significant after 7 days of treatment. The positive effect of metformin on differentiation was significant in osteoinducing conditions.

Conclusions. Metformin can be applied as an additional osteoinductive factor in bone regeneration treatment. Moreover, scaffolds with controlled release of metformin can be considered a proper osteoinductive bone substitute that may lessen the complications related to applying allograft scaffolds alone.

Keywords: allograft, dental pulp stem cells, tissue engineering, bone regeneration, metformin 


\section{Introduction}

Different types of bone materials have been used to treat major orthopedic and maxillofacial bone defects. ${ }^{1-3}$ Although their use produces fewer side effects (e.g., less morbidity, nerve damage, bleeding, infection, and loss of function) in comparison with autogenous bone grafts, ${ }^{4,5}$ they lack essential osteoinductive factors to be utilized as bone-grafting progenitor cells. ${ }^{6}$ However, freeze-dried bone allografts (FDBAs) possess osteoinductive growth factors, such as bone morphogenic proteins., ${ }^{4,6}$ Additionally, they have demonstrated the capability to recruit bone-forming progenitor cells and support them following differentiation. ${ }^{6}$ Despite this capability, they still have less osteogenic capacity than autogenous bone grafts, which leads to slower new bone formation in the defective site. ${ }^{7,8}$ Hence, attempts have been made to find a solution to improve the osteogenic ability of FDBA granules. ${ }^{9-11}$ Unfortunately, they were not effective in vivo. ${ }^{12-15}$

It has been proven that metformin, an insulin-inducing agent, can increase mineralization and osteogenic differentiation. In fact, metformin can activate 5' adenosine monophosphate (AMP)-activated protein kinase (AMPK), which regulates osteoblast differentiation in specific tissues. ${ }^{16}$ Several studies have evaluated the effect of metformin, and described its positive effect on the proliferation and osteogenic differentiation of stem cells in vitro. ${ }^{17-20}$ The enhancing effect of metformin on new bone formation has also been analyzed in in vivo conditions. ${ }^{21}$ It has been shown that the application of metformin helps to prevent the development of periodontitis through its osteoinductive features and its ability to regulate blood glucose. ${ }^{22}$

In this study, in order to enhance the osteogenic potential of FDBA materials, metformin, an osteogenic factor, was added to the medium. Human dental pulp stem cells (hDPSCs), a suitable cell source for regenerative treatment, ${ }^{23-25}$ were used. This study evaluated the effect of metformin on the proliferation, osteogenic differentiation and adhesion of DPSCs cultured on FDBA granules.

\section{Material and methods}

Ethical permission was obtained from the Ethics Committee of Shahid Beheshti Medical University in Tehran, Iran (Code: IR.SBMU.DRC.REC.1395.324).

\section{Isolation and characterization of human DPSCs}

Dental pulp stem cells at passage 3 were purchased from the Dental Research Center of Shahid Beheshti University of Medical Sciences. A high expression of mesenchymal stem cell markers (CD44, CD90, CD73, and CD105; Abcam, Cambridge, UK) and a low expression of hematopoietic cell markers (CD34 and CD45; Abcam) were characterized through flow cytometry analyses. The multilinear differentiation capacity of the cells was investigated through osteogenic and adipogenic differentiation tests. The cells were cultivated in standard Dulbecco's Modified Eagle's Medium-high glucose (DMEM-HG) with 15\% fetal bovine serum (FBS) (Invitrogen, Carlsbad, USA) and 1\% penicillin/streptomycin 10,000 U/mL (Life Technologies, Carlsbad, USA) at $37^{\circ} \mathrm{C}$ in a humidified $5 \%$ carbon dioxide environment. When the cultures reached $90 \%$ confluence, the cells were detached using $0.25 \%$ trypsin plus ethylene diamine tetraacetic acid (EDTA) (Life Technologies), and passaged for the following experiments.

\section{Pilot study}

Considering the dose-dependent effect of metformin, $100 \mu \mathrm{mol} / \mathrm{L}$ metformin hydrochloride (Alborz Pharmaceutical Co., Tehran, Iran) was chosen based on a previous study. ${ }^{19}$ The positive effect of this concentration of metformin on the proliferation and differentiation of DPSCs was evaluated. In brief, the cells at a density of $10^{4}$ were seeded in 48 -well plates with $100 \mu \mathrm{mol} / \mathrm{L}$ metformin hydrochloride, and either the standard medium was added for the proliferation assay or the osteogenic medium for the differentiation assay. Proliferation was evaluated with the 3-(4,5-dimethylthiazol-2-yl)-2,5diphenyltetrazolium bromide (MTT) (Sigma Aldrich, St. Louis, USA) assay after 1, 3 and 7 days of treatment with or without metformin. Osteogenic differentiation was evaluated using an alkaline phosphatase (ALP) activity kit (Sigma Aldrich) after 3, 7 and 14 days. Similar to the proliferation assay, DPSCs cultured in the osteogenic medium only (DMEM-low glucose (LG), $0.2 \mathrm{~mol} / \mathrm{L}$ ascorbic acid 2-phosphate, $10^{-8} \mathrm{~mol} / \mathrm{L}$ dexamethasone, and $10 \mathrm{mmol} / \mathrm{L} \beta$-glycerol phosphate; Life Technologies), without metformin, were used as a control for pairwise comparisons at each time point.

\section{Cell seeding}

Particulate cortical/cancellous mineralized 1-2-millimeter FDBA granules (Tissue Regeneration Corporation, Tehran, Iran) were placed in 48-well plates and a cell suspension including $2.5 \times 10^{4}$ DPSCs was loaded into the wells. The plates were incubated at $37^{\circ} \mathrm{C}$ for $1 \mathrm{~h}$. Then, according to the type of evaluation, 2 kinds of media (standard or osteogenic) were added to the wells. The osteogenic medium included DMEM-LG, $0.2 \mathrm{~mol} / \mathrm{L}$ ascorbic acid 2-phosphate, $10^{-8} \mathrm{~mol} / \mathrm{L}$ dexamethasone, and $10 \mathrm{mmol} / \mathrm{L} \beta$ glycerol phosphate (Life Technologies). Next, $100 \mu \mathrm{mol} / \mathrm{L}$ metformin hydrochloride was added to the samples. The study groups and the content of the wells are summarized in Table 1. 
Table 1. Study groups

\begin{tabular}{|l|c|c|}
\hline \multicolumn{1}{|c|}{ Group } & Ingredients & Tests \\
\hline FDBA + Met & FDBA + Met + hDPSCs & SEM, MTT, ALP activity \\
FDBA & FDBA + hDPSCs & SEM, MTT, ALP activity \\
\hline
\end{tabular}

FDBA - freeze-dried bone allograft; Met - metformin; hDPSCs - human dental pulp stem cells; SEM - scanning electron microscopy; MTT - 3-(4,5-dimethylthiazol-2-yl)-2,5-diphenyltetrazolium bromide; ALP - alkaline phosphatase.

\section{Cell adhesion}

The adhesion of DPSCs was evaluated with a scanning electron microscope (SEM) (VEGA; Tescan, Brno, Czech Republic) at $\times 1,000$ and $\times 2,000$ magnifications 1 and 7 days after cell seeding. After being rinsed with phosphate-buffered sodium (PBS) (Sigma Aldrich), the cells were fixed for $2 \mathrm{~h}$ in $2.5 \%$ glutaraldehyde and for $1 \mathrm{~h}$ in $1 \%$ osmium. The samples were then dehydrated with ascending grades $(30 \%, 50 \%, 70 \%, 90 \%, 95 \%$, and $100 \%$ ) of ethanol and dried in a desiccator for $24 \mathrm{~h}$. Finally, they were covered with gold and analyzed using SEM imaging.

\section{Cell proliferation}

In order to evaluate cell viability, the MTT assay was performed 1, 3 and 7 days after seeding. First, the granules were transferred to new wells to avoid counting the cells adhering to the bottom of the plate. Then, MTT was added to the wells and the plates were incubated at $37^{\circ} \mathrm{C}$ for $4 \mathrm{~h}$. Next, they were incubated with dimethyl sulfoxide (Carlo Erba Reagents, Milan, Italy) overnight. The supernatants were collected and transferred to 96-well plates, and absorbance was read using a microplate reader (Anthos Labtec Instruments, Salzburg, Austria) at a wavelength of $590 \mathrm{~nm}$.

\section{Cell differentiation}

The osteogenic differentiation of the stem cells was evaluated 3,7 and 14 days after cell seeding using an ALP activity kit. This test was performed on the cells seeded in both the non-inducing and inducing media. The cell-scaffold constructs were rinsed twice with PBS, homogenized in lysis buffer $(10 \mathrm{mmol} / \mathrm{L}$ Tris- $\mathrm{HCl}$ - pH 7.5, $1 \mathrm{mmol} / \mathrm{L} \mathrm{MgCl}_{2}$ and $0.05 \%$ Triton X-100) and centrifuged at $12,000 \mathrm{rpm}$ for $10 \mathrm{~min}$ at $4^{\circ} \mathrm{C}$. The cell lysate was mixed and incubated with the ALP assay reagent at $37^{\circ} \mathrm{C}$ for $30 \mathrm{~min}$, and the absorbance of the resulting ALP activity was quantified by calculating the optical density values at $405 \mathrm{~nm}$. It must be mentioned that the reaction was stopped using $0.5 \mathrm{~N}$ sodium hydroxide.

\section{Statistical analysis}

The Mann-Whitney $U$ test was used to compare the MTT values. The Kruskal-Wallis test was performed for the multiple group comparison. Data was analyzed using the PASW Statistics for Windows computer software, v. 18.0 (SPSS Inc., Chicago, USA), at a significance level of 0.05 .

\section{Results}

\section{Pilot study}

The positive effect of metformin on the proliferation and differentiation of DPSCs was evaluated in this phase of the study. The proliferation of DPSCs in the metformin group was higher than that in the control group at each time point, but the difference was significant only at day 1 $(p=0.00)$ (Fig. 1). An increase in the number of cells from day 1 to day 7 demonstrated the biocompatibility of this concentration of metformin $(p=0.00)$. In addition, just as with proliferation, the ALP activity of the metformin group was higher as compared to the control group in the osteogenic medium $(p=0.00)$, but the difference between the groups was not significant in the standard medium (Fig. 2). Moreover, it was shown that the osteogenic medium increased the differentiation of both the control and metformin groups ( $p=0.00$ ) (Fig. 2).

\section{Cell adhesion}

The micro-images of the unloaded scaffolds are depicted in Fig. 3. Freeze-dried bone allograft granules had a lamellar texture and a pore size of $50-500 \mu \mathrm{m}$. As can be observed in Fig. 3, SEM confirmed the strong attachment of DPSCs to FDBA granules in the presence of metformin.

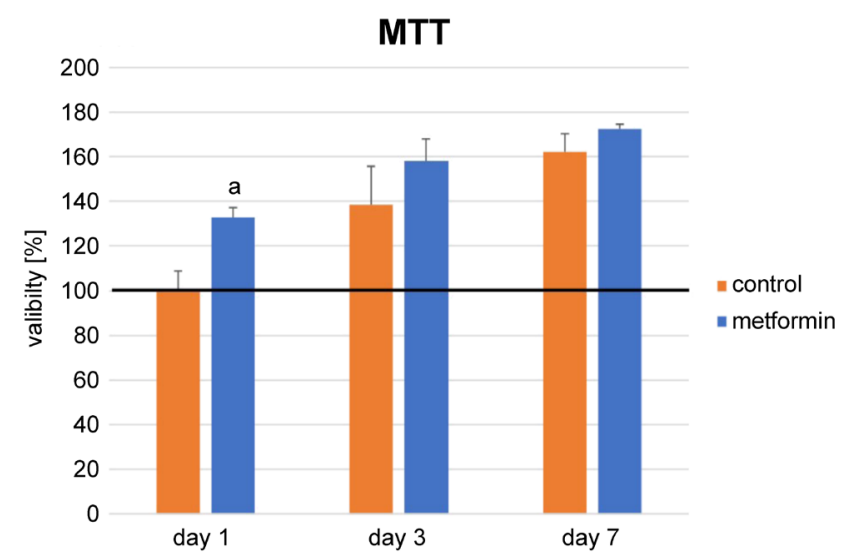

Fig. 1. Comparison of cell viability between the metformin and control groups at different time points

a statistically significant difference vs control $(p<0.05)$; the error bar represents 95\% confidence interval (Cl). 


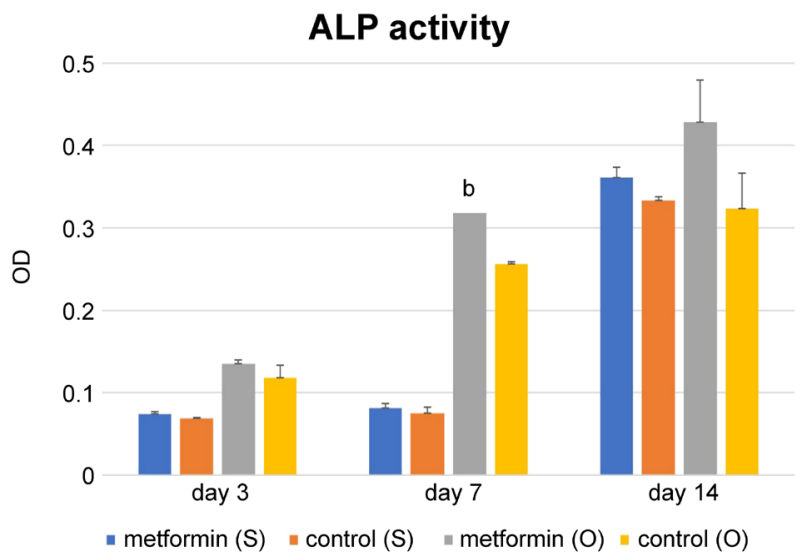

Fig. 2. Comparison of alkaline phosphatase (ALP) activity between the metformin and control groups at different time points

OD - optical density; S - standard medium; O - osteogenic medium; ${ }^{\mathrm{b}}$ statistically significant difference vs control $(\mathrm{O})(p<0.05)$; the error bar represents $95 \% \mathrm{Cl}$.
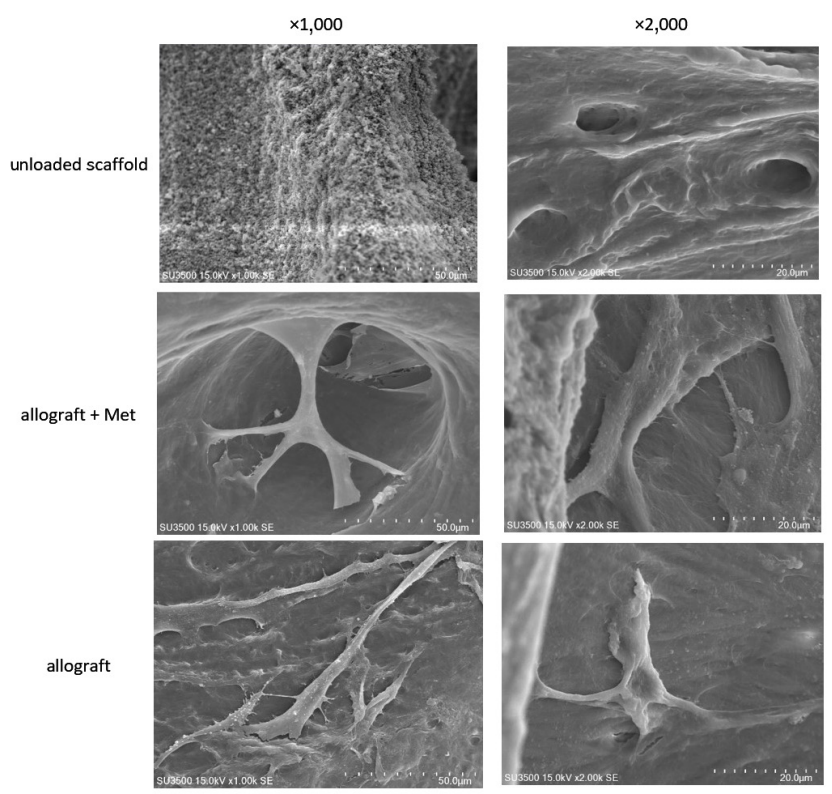

Fig. 3. Scanning electron microscope (SEM) images of the scaffolds 7 days after cell seeding

\section{Cell proliferation}

Cell viability increased from day 1 to day 7 in all groups $(p=0.00)$ (Fig. 4). The FDBA + metformin (Met) group showed higher proliferation at each time point. However, the difference was significant only at day 7 following cell seeding $(p=0.004)$.

\section{Cell differentiation}

Alkaline phosphatase activity increased in all groups 7 days after cell seeding, in both the inducing and noninducing media. After 3 days, the FDBA + Met group showed a lower ALP activity in the osteogenic medium, but the difference was not statistically significant.

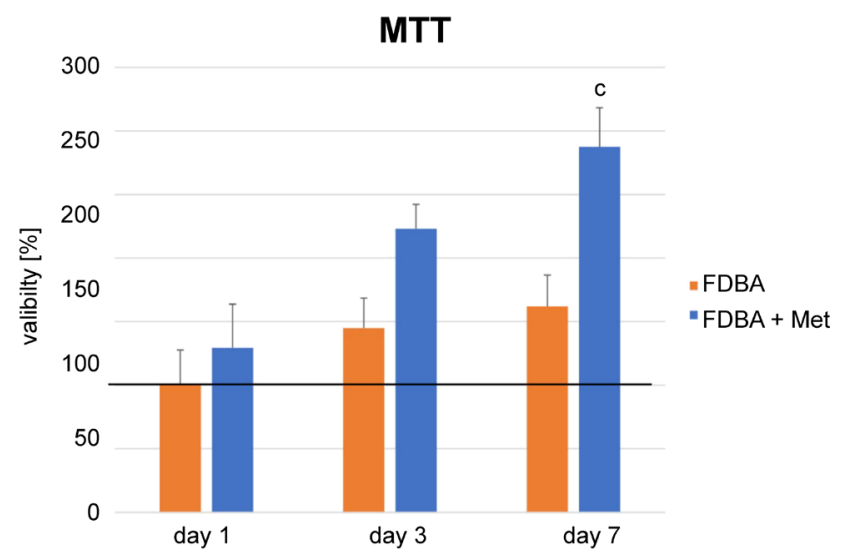

Fig. 4. Comparison of cell viability between the freeze-dried bone allograft (FDBA) + metformin (Met) and FDBA groups at different time points

c statistically significant difference vs FDBA ( $p<0.05)$; the error bar represents $95 \%$ Cl.

However, after 7 days, the FDBA + Met group showed a significantly higher ALP activity in osteogenic conditions only $(p=0.01)$. Using the osteogenic medium increased ALP activity significantly in both groups $(p=0.00)$, but 14 days following cell seeding, the difference was not significant. In addition, 14 days following cell seeding, there was no significant difference in the ALP activity rate between the FDBA and FDBA + Met groups (Fig. 5). Thus, it was shown that the positive effect of metformin on differentiation was significant in osteoinducing conditions.

\section{Discussion}

The success of regeneration treatment depends on providing a suitable environment for the attachment, proliferation and differentiation of stem cells. Proper interactions between stem cells, growth factors and scaffolds are essential to reach this goal. Freeze-dried bone allograft

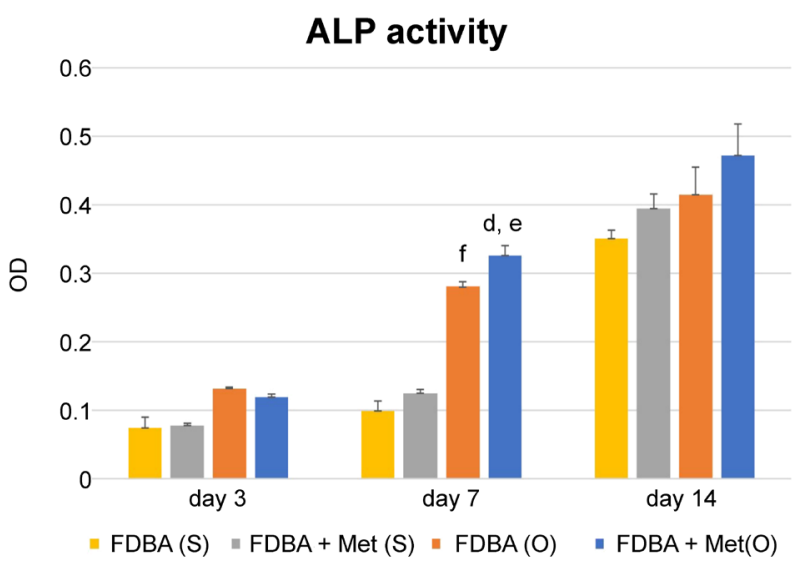

Fig. 5. Comparison of ALP activity between the metformin and control groups at different time points

d statistically significant difference vs FDBA $(O)(p<0.05) ;{ }^{\text {e }}$ statistically significant difference vs FDBA + Met $(S)(p<0.05)$; ${ }^{\text {s }}$ statistically significant difference vs FDBA $(S)(p<0.05)$; the error bar represents $95 \% \mathrm{Cl}$. 
granules have less osteogenic capacity in comparison with autogenous bone grafts. Thus, several studies have been conducted to enhance the osteogenic ability of these granules. The aim of this study was to evaluate the effect of metformin on the adhesion, proliferation and differentiation of DPSCs cultured on FDBA granules. The results showed that metformin could enhance the adhesion, proliferation and differentiation of DPSCs on FDBA granules in inducing conditions.

Houshmand et al. evaluated the effect of metformin on the proliferation, differentiation and adhesion of DPSCs on macroporous biphasic calcium phosphate granules. ${ }^{19}$ They performed a pilot study to determine the proper concentration of metformin. They stated that $100 \mu \mathrm{mol} / \mathrm{L}$ increased the proliferation of DPSCs the most. In addition, they analyzed ALP activity and used the MTT assay to evaluate differentiation and proliferation, respectively. ${ }^{19}$ As the present study found, metformin increased proliferation in the presence or absence of the scaffold, and had no significant effect on the differentiation of DPSCs cultured in the non-inducing medium. However, in the inducing medium, metformin increased differentiation.

Several studies have been performed to identify a proper growth factor for enhancing the osteogenic capacity of FDBA granules. Markopoulou et al. noted that recombinant human transforming growth factor-beta 1 (rhTGF- 1 1) enhanced the osteogenic differentiation of human periodontal ligament cells (hPDLCs) cultured on FDBA granules. ${ }^{10}$ In addition, Cenni et al. found that platelet-rich plasma (PRP) had a positive effect in in vitro conditions. ${ }^{9}$ However, according to in vivo results, PRP had no significant positive effect on the osteogenesis of bone mesenchymal stem cells (BMSCs) cultured on FDBA granules. ${ }^{15}$ Thus, our claim that metformin has a positive effect on osteogenesis in vitro should be analyzed in vivo as well.

Besides in vitro studies, several studies have been conducted to improve the osteogenic capacity of FDBA granules in vivo. Borie et al. evaluated the effect of autogenous particles and FDBA granules on osteogenesis, using a rabbit calvarial defect model. ${ }^{14}$ They found that FDBA granules caused lamellar bone formation after 90 days, while a mixture of autologous particles and FDBA granules caused woven bone formation over the same period of time. ${ }^{14}$ In addition, Dallari et al. mentioned in their study that PRP did not enhance the osteogenic capacity of FDBA granules in rabbit trabecular defects. ${ }^{15}$ Choukroun et al. found that PRP had no positive effect on the osteogenic capacity of FDBA granules in sinus lift procedures. ${ }^{12}$ In addition, Samandari et al. mentioned no positive effect for plasma-rich growth factor on the osteoinductive ability of FDBA during socket preservation. ${ }^{13}$ Thus, more in vivo studies are required to determine a proper material for improving the osteogenic capacity of FDBA granules.
The time- and concentration-dependent effects of metformin on the behavior of stem cells have been proven. ${ }^{26} \mathrm{How}-$ ever, a particular concentration of metformin does not seem to have the same effect on different types of stem cells. For instance, Śmieszek et al. stated that metformin at concentrations of $100 \mu \mathrm{M}$ and $500 \mu \mathrm{M}$ did not affect the proliferation of BMSCs significantly, while $10 \mu \mathrm{M}$ metformin decreased proliferation. ${ }^{26}$ However, Wang et al. found that $10 \mu \mathrm{M}$ metformin had no significant effect on the viability of humaninduced pluripotent stem cell-derived mesenchymal stem cells (hiPSC-MSCs). ${ }^{20}$ Zhang et al. mentioned that the $10 \mu \mathrm{M} / \mathrm{L}$ and $50 \mu \mathrm{M} / \mathrm{L}$ concentrations of metformin had no significant effect on the proliferation of periodontal ligament stem cells (PDLSCs), but $100 \mu \mathrm{M} / \mathrm{L}$ metformin increased proliferation. ${ }^{17}$ In fact, due to the saturation of ligands, higher concentrations of metformin cannot promote its effects. ${ }^{27}$ Besides, higher concentrations of metformin may have adverse effects on the energy metabolism of cells, and result in a decrease in proliferation and differentiation. ${ }^{17,28}$

The exact molecular mechanism of metformin is still unclear. Mu et al. proposed that metformin could enhance differentiation and proliferation through AMPK-mammalian target of rapamycin Complex 2 (AMPK-mTORC2) and Akt-mTOR Complex 1 (Akt-mTORC1) signaling pathways. ${ }^{29}$ However, Ma et al. stated that metformin increased the osteogenic differentiation of BMSCs by inhibiting glycogen synthase kinase 3 beta (GSK3 $\beta$ ) and Wnt signaling pathways. ${ }^{18}$ In addition, they mentioned that AMPK played a crucial role in the abovementioned procedure. ${ }^{18}$ Several other studies have mentioned that metformin induces osteogenic differentiation through AMPK and mitogenactivated protein kinase (MAPK) pathways. ${ }^{20,21,29,30}$ Thus, there is still controversy over the intracellular pathways regarding the effect of metformin.

In this study, the effect of metformin on the behavior of DPSCs was evaluated. Several other studies have been conducted to assess the reaction of other types of cells to metformin. The positive effect of metformin on the proliferation and differentiation of murine pre-osteoblasts, ${ }^{29}$ PDLSCs, ${ }^{31} \mathrm{BMSCs}^{32}$ and induced pluripotent stem cells ${ }^{20}$ has been described. In addition, Qin et al. showed that besides osteogenic differentiation, metformin could enhance the odontogenic differentiation of DPSCs. ${ }^{33,34}$

Considering the limitations of applying autogenous bone grafts, a wide range of natural and synthetic scaffolds has been used in bone regeneration treatment. ${ }^{2}$ However, due to the lower osteogenic capacity of these scaffolds in comparison with autogenous grafts, applying them by themselves has yet to be considered. ${ }^{6}$ The addition of growth factors, one of the fundamental components of tissue engineering besides stem cells and scaffolds, can be deemed a possible method for enhancing the osteoinductivity of bone substitutes. In this study, a significant positive effect of metformin was shown in vitro. Therefore, this factor may improve the efficacy of both natural and synthetic scaffolds in vivo. 
Since this study was performed in vitro, factors related to the recipient features, including the mechanical features of the tissue, possible inflammation, a heterogeneous tissue environment, and interactions between different cell types, were not considered. Therefore, for generalizing the results to in vivo conditions, performing animal and clinical studies is necessary.

\section{Conclusions}

The positive effect of metformin on cell proliferation and differentiation, in conjunction with FDBA granules, would be useful for its future application in fabricating FDBA granules with controlled release of this osteoinductive factor for bone tissue engineering. Besides, metformin can be applied in bone regeneration treatment to enhance osteogenesis.

\section{ORCID iDs}

Farnaz Kouhestani (1) https://orcid.org/0000-0002-9341-1209 Maryam Rezai Rad (1) https://orcid.org/0000-0001-6998-4499 Sadra Mohaghegh (1) https://orcid.org/0000-0002-4494-5685 Saeed Reza Motamedian (1) https://orcid.org/0000-0001-7337-2145

\section{References}

1. Damien $\mathrm{CJ}$, Parsons JR. Bone graft and bone graft substitutes: A review of current technology and applications. J Appl Biomater. 1991;2(3):187-208. doi:10.1002/jab.770020307

2. Khojasteh A, Motamedian SR, Rezai Rad M, Shahriari MH, Nadjmi N. Polymeric vs hydroxyapatite-based scaffolds on dental pulp stem cell proliferation and differentiation. World J Stem Cells. 2015;7(10):1215-1221. doi:10.4252/wjsc.v7.i10.1215

3. Kouhestani F, Dehabadi F, Shahriari MH, Motamedian SR. Allogenic vs. synthetic granules for bone tissue engineering: An in vitro study. Prog Biomater. 2018;7(2):133-141. doi:10.1007/s40204-018-0092-3

4. Miron RJ, Zhang YF. Osteoinduction: A review of old concepts with new standards. J Dent Res. 2012;91(8):736-744. doi: $10.1177 / 0022034511435260$

5. Nkenke E, Schultze-Mosgau S, Radespiel-Tröger M, Kloss F, Neukam FW. Morbidity of harvesting of chin grafts: A prospective study. Clin Oral Implants Res. 2001;12(5):495-502. doi:10.1034/j.16000501.2001.120510.x

6. Wei L, Miron RJ, Shi B, Zhang Y. Osteoinductive and osteopromotive variability among different demineralized bone allografts. Clin Implant Dent Relat Res. 2015;17(3):533-542. doi:10.1111/cid.12118

7. Mellonig JT, Bowers GM, Cotton WR. Comparison of bone graft materials. Part II. New bone formation with autografts and allografts: A histological evaluation. J Periodontol. 1981;52(6):297-302. doi:10.1902/jop.1981.52.6.297

8. Oklund SA, Prolo DJ, Gutierrez RV, King SE. Quantitative comparisons of healing in cranial fresh autografts, frozen autografts and processed autografts, and allografts in canine skull defects. Clin Orthop Relat Res. 1986;205:269-291.

9. Cenni E, Perut F, Ciapetti G, et al. In vitro evaluation of freeze-dried bone allografts combined with platelet rich plasma and human bone marrow stromal cells for tissue engineering. J Mater Sci Mater Med. 2009;20(1):45-50. doi:10.1007/s10856-008-3544-9

10. Markopoulou CE, Dereka XE, Vavouraki HN, et al. Effect of rhTGF- $\beta 1$ combined with bone grafts on human periodontal cell differentiation. Growth Factors. 2011;29(1):14-20. doi:10.3109/08977194.2010.533663

11. Markopoulou CE, Vrotsos IA, Vavouraki HN, Dereka XE, Mantzavinos ZS. Human periodontal ligament cell responses to recombinant human bone morphogenetic protein-2 with and without bone allografts. J Periodontol. 2003;74(7):982-989. doi:10.1902/jop.2003.74.7.982
12. Choukroun J, Diss A, Simonpieri A, et al. Platelet-rich fibrin (PRF): A second-generation platelet concentrate. Part V: Histologic evaluations of PRF effects on bone allograft maturation in sinus lift. Oral Surg Oral Med Oral Pathol Oral Radiol Endod. 2006;101(3):299-303. doi:10.1016/j.tripleo.2005.07.012

13. Samandari MH, Haghighat A, Torabinia N, Taghian M, Sadri L, Naemy V. Socket preservation using freeze-dried bone allograft with and without plasma rich in growth factors in dogs. Dent Res $J$ (Isfahan). 2016;13(5):432-439.

14. Borie E, Fuentes R, Del Sol M, Oporto G, Engelke W. The influence of FDBA and autogenous bone particles on regeneration of calvaria defects in the rabbit: A pilot study. Ann Anat. 2011;193(5):412-417. doi:10.1016/j.aanat.2011.06.003

15. Dallari D, Fini M, Stagni $C$, et al. In vivo study on the healing of bone defects treated with bone marrow stromal cells, platelet-rich plas$\mathrm{ma}$, and freeze-dried bone allografts, alone and in combination. J Orthop Res. 2006;24(5):877-888. doi:10.1002/jor.20112

16. Jang WG, Kim EJ, Bae IH, et al. Metformin induces osteoblast differentiation via orphan nuclear receptor SHP-mediated transactivation of Runx2. Bone. 2011;48(4):885-893. doi:10.1016/j.bone.2010.12.003

17. Zhang R, Liang Q, Kang W, Ge S. Metformin facilitates the proliferation, migration, and osteogenic differentiation of periodontal ligament stem cells in vitro. Cell Biol Int. 2019. doi:10.1002/cbin.11202

18. Ma J, Zhang ZL, Hu XT, Wang XT, Chen AM. Metformin promotes differentiation of human bone marrow derived mesenchymal stem cells into osteoblast via GSK3 $\beta$ inhibition. Eur Rev Med Pharmacol Sci. 2018;22(22):7962-7968. doi:10.26355/eurrev_201811_16424

19. Houshmand B, Tabibzadeh Z, Motamedian SR, Kouhestani F. Effect of metformin on dental pulp stem cells attachment, proliferation and differentiation cultured on biphasic bone substitutes. Arch Oral Biol. 2018;95:44-50. doi:10.1016/j.archoralbio.2018.07.012

20. Wang P, Ma T, Guo D, et al. Metformin induces osteoblastic differentiation of human induced pluripotent stem cell-derived mesenchymal stem cells. J Tissue Eng Regen Med. 2018;12(2):437-446. doi:10.1002/term. 2470

21. Molinuevo MS, Schurman L, McCarthy AD, et al. Effect of metformin on bone marrow progenitor cell differentiation: In vivo and in vitro studies. J Bone Miner Res. 2010;25(2):211-221. doi:10.1359/jbmr.090732

22. Pradeep AR, Patnaik K, Nagpal K, et al. Efficacy of locally-delivered $1 \%$ metformin gel in the treatment of intrabony defects in patients with chronic periodontitis: A randomized, controlled clinical trial. J Investig Clin Dent. 2016;7(3):239-245. doi:10.1111/jicd.12150

23. Lee YC, Chan YH, Hsieh SC, Lew WZ, Feng SW. Comparing the osteogenic potentials and bone regeneration capacities of bone marrow and dental pulp mesenchymal stem cells in a rabbit calvarial bone defect model. Int J Mol Sci. 2019;20(20):5015. doi:10.3390/ijms20205015

24. Amghar-Maach S, Gay-Escoda C, Sánchez-Garcés MA. Regeneration of periodontal bone defects with dental pulp stem cells grafting: Systematic review. J Clin Exp Dent. 2019;11(4):e373-e381. doi:10.4317/jced.55574

25. Hernández-Monjaraz B, Santiago-Osorio E, Monroy-García A, LedesmaMartínez E, Mendoza-Núñez VM. Mesenchymal stem cells of dental origin for inducing tissue regeneration in periodontitis: A mini-review. Int J Mol Sci. 2018;19(4):944. doi:10.3390/ijms19040944

26. Śmieszek A, Czyrek A, Basinska K, et al. Effect of metformin on viability, morphology, and ultrastructure of mouse bone marrowderived multipotent mesenchymal stromal cells and Balb/3T3 embryonic fibroblast cell line. Biomed Res Int. 2015;2015:769402. doi:10.1155/2015/769402

27. Singh I, Swami R, Pooja D, Jeengar MK, Khan W, Sistla R. Lactoferrin bioconjugated solid lipid nanoparticles: A new drug delivery system for potential brain targeting. J Drug Target. 2016;24(3):212-223. doi:10.3109/1061186X.2015.1068320

28. Acikgoz E, Güler G, Camlar M, Oktem G, Aktug H. Glycogen synthase kinase-3 inhibition in glioblastoma multiforme cells induces apoptosis, cell cycle arrest and changing biomolecular structure. Spectrochim Acta A Mol Biomol Spectrosc. 2019;209:150-164. doi:10.1016/j.saa.2018.10.036

29. Mu W, Wang Z, Ma C, et al. Metformin promotes the proliferation and differentiation of murine preosteoblast by regulating the expression of sirt6 and oct4. Pharmacol Res. 2018;129:462-474. doi:10.1016/j.phrs.2017.11.020 
30. Cortizo AM, Sedlinsky C, McCarthy AD, Blanco A, Schurman L. Osteogenic actions of the anti-diabetic drug metformin on osteoblasts in culture. Eur J Pharmacol. 2006;536(1-2):38-46. doi:10.1016/j.ejphar.2006.02.030

31. Jia L, Xiong Y, Zhang W, Ma X, Xu X. Metformin promotes osteogenic differentiation and protects against oxidative stress-induced damage in periodontal ligament stem cells via activation of the Akt/Nrf2 signaling pathway. Exp Cell Res. 2020;386(2):111717. doi:10.1016/j.yexcr.2019.111717

32. Tang TT, Lu H, Dai KR. Osteogenesis of freeze-dried cancellous bone allograft loaded with autologous marrow-derived mesenchymal cells. Mater Sci Eng C Mater Biol Appl. 2002;20(1-2):57-61. doi:10.1016/S0928-4931(02)00013-9

33. Qin W, Chen JY, Guo J, et al. Novel calcium phosphate cement with metformin-loaded chitosan for odontogenic differentiation of human dental pulp cells. Stem Cells Int. 2018;2018:7173481. doi:10.1155/2018/7173481

34. Qin W, Gao X, Ma T, et al. Metformin enhances the differentiation of dental pulp cells into odontoblasts by activating AMPK signaling. J Endod. 2018;44(4):576-584. doi:10.1016/j.joen.2017.11.017 